\title{
Una aculturación plural indirecta: la herencia sefardita y española en la obra del escritor judío-argentino Alberto Gerchunoff
}

Norbert REHRMANN

Universität Gesamthochschule, Kassel

\author{
Alberto Gerchunoff fue un gran escritor, pero \\ el estilo de su fama trasciende la de un hombre \\ de letras \\ (Borges 1951:7)
}

1. De Rusia a la ARgentina Pasando por España: estacioNES BIOGRÁFICAS Y BIBLIOGRÁFICAS

A Alberto Gerchunoff (1883-1950), el judío askenazí originario de Rusia, se le ha considerado como el «Néstor» (Nesbit 1951:155) de la literatura judía de Argentina. En su homenaje que publicó la revista Davar poco después de su muerte se le menciona como «un elemento esencial en el arraigo judío en la Argentina ...» (Giusti 1951:6). A diferencia del héroe de la Odisea griega, patria etimológica del concepto de Néstor, es verdad que Gerchunoff no vivió tres generaciones. Pero la sorprendente variedad de su creación literaria ${ }^{1}$, sobre todo sus mundos culturales desconcertadoramente múltiples en los cuales se sentía más o menos simultáneamente como en casa, parecen no encontrar cabida en una sola persona. Por eso tiene razón Louis Nesbit (1951:114) cuando se refiere a Gerchunoff como el «caso particular de un escritor que con tanta facilidad parece asimilar el medio en que vive ... sin ser él un producto de la tierra que así interpreta, ni de la herencia que exalta».

1 «Gerchunoff»-escribe Louis NESBIT (1951:157)-, «fue un polígrafo por excelencia: periodista, filós ofo, humorista, satírico, novelista, crítico, costumbrista, poeta, ensayista, orador y comentarista político». 
Sorprenden los contenidos de esa «herencia", objeto de la presente reflexión: en primer lugar, la cultura sefardita del medioevo, que este askenazí nacido en Rusia reclamó para sí toda su vida, de la misma manera que todos los judíos de Latinoamérica; y en segundo lugar, lo que es aún más sorprendente, la cultura española como tal, mucho más allá de los límites de la producción estrictamente judía.

«Su veneración hispanófila», escribe Eduardo Senkman (1983: 264), es un elemento central del «acta de fundación de un pueblo» (1983:34). En la multiplicidad desconcertante -por lo menos en una primera impresión- de las orientaciones culturales de este judío ruso-askenazí, que además se consideraba un patriota argentino avant la lettre, pensaba probablemente Borges (1951:7) cuando escribía que «su fama trasciende la de un hombre de letras».

Las ya muchas páginas dedicadas a la investigación de la obra de Alberto Gerchunoff (Toker 1994:18ss) no se han ocupado, sin embargo, hasta hoy de las facetas que presenta en concreto su «veneración hispanófila». Esas facetas de su obra que marcan un capítulo asombroso y hasta hoy poco estudiado de la aculturación indirecta judía ${ }^{2}$, constituyen el núcleo central de las siguientes consideraciones.

\section{LOS GAUCHOS JUdíos Y EL LEGADO DE SEFARAD}

Cuando a los 8 años llega Alberto con su familia y otros numerosos judíos rusos a tierras argentinas ${ }^{3}$, dejando atrás la opresión zarista y la persecusión antisemita, no habla aún ni una palabra de español. Doce años después, a los 20, asume la redacción de un periódico de provincias. Con 25 entra a formar parte del equipo de colaboradores de La Nación de Buenos Aires y entre otras cosas publica allí relatos costumbristas que dos años después aparecen como libro bajo el título de Los gauchos judíos en homenaje a la Revolución de Mayo, es decir, al Centenario de la Independencia nacional del país, celebrado solemnemente.

\footnotetext{
2 Fenómeno parcialmente comparable es el de la «sefardización» de judíos askenazíes en la Alemania del siglo XIX (Rehrman 1999a), del cual me ocuparé en un próximo proyecto de investigación.

${ }^{3}$ Los primeros cuatro años los pasó en la colonia Rajil, fundada por el barón Hirsch en la provincia de Entre Ríos. Luego vivió principalmente en Buenos Aires.
} 
Los relatos sobre la colonia judía en la cual el propio autor había vivido lo hicieron de golpe conocido y, como lo sugiere el título, constituyen de forma muy clara «su verdadera carta de ciudadanía» (Senkman 1983:59) como judío y argentino.

Paso por alto aquí el mito del gaucho del libro ampliamente analizado ${ }^{4}$. Ciertamente sus implicaciones ideológicas apuntan en primer lugar al «espíritu del tiempo» argentino dentro del contexto del Centenario (1984:17ss), pero en lo que corresponde a la parte hispánica alcanzan una mayor profundidad.

En el inicio de la hispanofilia perpetua de Gerchunoff se encuentra al parecer el descubrimiento de don Quijote: un emigrante asturiano que había conocido en Buenos Aires cuando buscaba trabajo le hizo conocer el libro de los libros - «libro que lo deslumbra para toda la vida» (Toker 1994:11). En lo que se refiere al lenguaje, el fruto de tal descubrimiento cristaliza en la imitación - poco convincente- del estilo del célebre modelo: «El idioma de Gerchunoff», escribe Senkmann (1983:40), «se esfuerza por parecer cervantino, atravesado de arcaísmos ... además de hacer gala de un preciso uso de culturalismos».

La lengua, repetiría frecuentemente Gerchunoff, es «la verdadera nacionalidad», pues según propia convicción: «Los que somos judíos tan sólo por la herencia familiar, somos antes que nada ciudadanos de nuestros respectivos países" (Liacho 1951:78). Sin embargo, a lo largo de toda su vida el asunto de su nacionalidad será algo sumamente complejo. Como ya se puede apreciar claramente en sus inicios literarios con Los gauchos judíos, el concepto de nacionalidad trasciende ampliamente la dimensión del lenguaje.

Según sus propias palabras, hay que tener en cuenta por un lado su íntimo afecto y apego a la Argentina, «un amor fervoroso al suelo todavía desconocido (que) rebosaba en todas las almas» (1984:167); un «amor» que en su origen se debía al refugio que el país le concedía contra la persecución antisemita ${ }^{5}$, pero que llegaría a convertirse en un ferviente patriotismo a pesar de sus amar-

${ }^{4}$ Cf. Senkmann (1983) y Aizenberg (1991).

5 "Me acuerdo», como dice un rabino ficticio de la primera colonia de judios rusos en la provincia de Entre Ríos, «que en la ciudad de Kischenef, después de la matanza de judíos, la sinagoga fué cerrada porque no quisimos bendecir la República y bendecimos al Presidente» (1984:171). 
gas experiencias con variantes argentinas de antisemitismo ${ }^{6}$. Por otro lado, su amor a España «(que) simbolizaba ... la libertad de los pueblos» (1984:172), por decirlo así la apoteosis histórica de las esperanzas que él asociaba con la Argentina.

A diferencia de escritos posteriores, en Los gauchos judíos figura España casi exclusivamente como «conexión judía» (Angel 1995:354ss), como recuerdo (1984:159) de «las épocas castizas en que los hebreos formaban, en las villas españolas, doctas corporaciones de sabios y poetas». Es omnipresente el recuerdo del siglo de oro español de acuñación judía ${ }^{7}$ (1984:116), borrando incluso aquí o allá las fronteras entre realidad y ficción: «Esa exaltación de lo judeo-español ... en Los gauchos judíos», escribe Toker (1994:135), «llega hasta el extremo de situar en Castilla a rabí Akiva, uno de los sabios que redactaron el Talmud de Jerusalem ...». Uno de los descendientes de este rabino «pomposo y sutil», cuenta (1984:11) a los habitantes de la colonia las «disquisiciones medievales de Toledo y de Córdoba, conduciendo al auditorio el pensamiento florido y profundo de los judíos que continuaron bajo los reyes de Castilla, la tradición de los doctores de Jerusalem».

Ya aquí en la obra temprana de Gerchunoff se nota que habla solamente de la «segunda convivencia», es decir del apogeo de la Toledo cristiana (1984:162) «en que nuestros hermanos vivían tranquilos al amparo de los reyes de Castilla».

Frente a ello casi no se menciona a Al-Ándalus, la época de sello moro de los califas de Córdoba y de los posteriores reinos de taifas. Esta estrecha y contraída perspectiva del «país de las tres culturas» la conservó Gerchunoff también en sus publicaciones posteriores; y así, por ejemplo, escribe en un ensayo sobre «El espíritu judío en la cultura española» del año 1940: «Conservaba el judío en España sus costumbres religiosas, sus aislamientos civiles, pero ... convivía con el hermano cristiano sin desconfianza recíproca, sin obstáculos, sin resquemores equívocos» (1940:142).

\footnotetext{
${ }^{6}$ En los Los gauchos judios (1984:169) describe Gerchunoff el patriotismo de sus correligionarios con un guiño irónico al referirse a la contribución judía al Centenario de 1910: ninguno de los colonos hablaba español, ninguno sabía exactamente lo que significaba la fecha; el comité judío de la preparación del festejo ni siquiera conocía los colores de la bandera argentina, lo que no perjudicó en lo mínimo su solemne contribución: «Cada uno explicaba a su modo la importancia del suceso ...».

7 Cf. Tietz (1998).
} 
En cambio la influencia islámica en la época cimera del medioevo tardío la comenta (1940:146) con una frase subordinada: «Y yo que, desgraciadamente, no puedo juzgar el valor de la producción en lengua arábiga, me solazo siempre con lo que han producido los judíos en lengua española ...». Sí valora correctamente la producción cultural judía en Sefarad cuando escribe: «Hay grandes escritores judíos en lengua francesa y germánica, en lengua italiana; ninguno de ellos ha alcanzado la multiplicidad, la generosidad, la virtud, que ofrece el judío en la filosofía, en el pensamiento y en la poesía, en el idioma español» (1940:146).

La influencia judía en la cultura española, silenciada y negada durante largo tiempo, es omnipresente y aparece tanto en numerosas «ocupaciones cotidianas, según las llamaba Fray Luis de León» (1984:148) -por ejemplo, en la agricultura- como en la religión, «(donde hay) influencias netamente judías». Puede ilustrarse bien dicha influencia por medio de la célebre oración de defensa de Fray Luis de León (1940:147): «Yo no sé, maestro, si tengo sangre judía, pero si tengo sangre judía soy mejor que vuestra merced porque tengo sangre dos veces cristiana».

Sin embargo la vena principal de la influencia judía la localiza Gerchunoff (1940:147) en la literatura y precisamente en algunas de las obras maestras que aparecieron después de 1492: "Con Fernando de Rojas, nos hallamos en la historia literaria de España en presencia de un acontecimiento de tanta fecundidad e importancia universal y local, como lo es la aparición de "La Celestina", que encierra un vasto germen del teatro español ${ }^{8}$ y el germen primero del más glorioso género literario de España, que es la novela picaresca».

En un temprano artículo sobre «Los judíos en la lengua castellana» (1952:31ss) todavía avanzó Gerchunoff un paso más al considerar a los judíos como los verdaderos padres fundadores de la literatura española: «Las primeras antologías poéticas de España fueron hechas por judíos. Don Francisco de Baena era judío - 'judino', como lo decía él mismo-. Judío era el agudo y atravesado coplero Montoro; judío el prodigioso creador de "La Celestina" ...".

Se ha conservado hasta el presente el deseo ardiente del judío

${ }^{8}$ Lamentablemente, escribe GeRCHUNOFF (1940:147), llegó Ramiro de Maeztu en su enjuiciamiento de este «milagroso libro» a una "conclusión antijudía», porque en él ve sobre todo «los rasgos sombríos del genio semítico». 
hacia esa «patria mágica» con el que construye un puente hasta la Argentina: «¿Será acaso por esto que el judío en la América hispánica, en la Argentina, se adapta con tanta prontitud al uso eficaz del idioma? Yo diría que no se adapta, lo que hace es recobrar un idioma que ya fué suyo ...» (1952:32).

Sin embargo, por lo que se refiere a la herencia española el mayor entusiasmo de Gerchunoff se manifiesta especialmente en lo que formula patéticamente (1953:14) como «el dogma de la religión quijotil». En esta formulación sin ningún ápice de ironía vibra no solamente la admiración por el estilo cervantino que trató de imitar a lo largo de toda su vida. En el «dogma» de la secularizada "religión-Quijote» se articula también el credo del autor por España. Los elementos históricos-culturales ${ }^{9}$ de este credo se oponen inesperadamente al elogio a la hispanidad formulado en otro lugar.

En los dos protagonistas novelescos, especialmente en don Quijote, encuentra «el espíritu español» en su casi pureza cultural, un espíritu hacia el que el autor judío Gerchunoff (1953:22) se mostraba especialmente receptivo: «Su locura consiste tan sólo en el medio elegido para practicar sus sentimientos: así como su cristianismo escueto y rígido no reconoce a la Santa Hermandad ...».

La referencia al inconformismo religioso de Cervantes constituye el eje principal de su interpretación de El Quijote, como cuando dice en relación con el pasaje de la quema de libros al comienzo de la novela: «No entreguéis los libros a las llamas ... Será trabajo perdido», oponiéndose (1953:81ss) al «señor obispo Barrientos» y al «señor licenciado y maese Nicolás», y continúa: «esas llamas, avergonzadas de su oficio inquisitorial, se transforman en seguida en infinita lupa roja que aumenta y proyecta el esplendor del sentimiento perseguido y del pensamiento prohibido. La ceni$z a$, que es su inesperado sepulcro, se vuelve a su vez viviente, próspera llama de libertad».

En lo que concierne al insinuado anti-conformismo religioso de Cervantes, la interpretación del célebre pasaje de la novela como «autos de fe» y «llama inquisitorial» puede que resulte exagerada y patético su estilo. Sin embargo en ella puede suponerse una

9 Únicos de los que voy a ocuparme aquí, dejando de lado otros temas no menos interesantes, como por ejemplo la estética popular de Cervantes (1953:26ss) o sus ideas sobre la justicia social (1953:48ss). 
genuina forma judía de lectura que aquí y allá evoca también a otras minorías, como la de los moriscos, que también fueron víctimas de la unidad religiosa y política.

Parece como si a Cervantes lo hubiera convertido nuestro autor en testigo principal de una imagen histórica tradicionalista en la cual las facetas moriscas aparecen solamente como clichés negativos: «Años enteros gimió en la cautividad del moro», dice resumiendo (1953:49) la prisión en el norte de Africa del creador de Don Quijote, «que así cobraba en el valiente ya inerme la proeza de Lepanto ...». En esa visión parcial y acentuadamente negativa del «moro» no habría de quedarse: teniendo como ejemplo $L a$ gitanilla de Cervantes, muestra (1953:54ss) también su reverencia a la cultura mora, aunque solamente como reminiscencia erótica: «Don Miguel de Cervantes, que anduvo por los barrios equívocos de Sevilla y estuvo en Argel, resurgió en su Gitanilla las moras con que soñaban los españoles y resumió en su gracia ligera, en su cuerpo movedizo, en su acento candoroso y picante a la vez, a las mil heroínas de la fantasía, a los seres creados por los poetas».

Esta interpretación puede parecer audaz; pero la represión de la sensualidad hispano-árabe tal y como Gerchunoff la vio concretizada en esta figura femenina cervantina, resiste ampliamente los resultados de la investigación histórica ${ }^{10}$ : «España había expulsado a los infieles. Pero ... la imagen de la mora aparecía en el recuerdo como una pesadilla. Se encarnaba en la gitana bailadora y revivía en todos la poesía de los amores orientales ${ }^{11}$, la sed de lo extraño, el afán de lo desconocido».

El retorno literario de lo reprimido toma también en El Quijote la forma de una mujer mora: Zoraida, escribe Gerchunoff (1953:63), «libra al cautivo y se hace cristiana, es decir, realiza el doble ideal del español de este tiempo y a la vez compensa con su hermosura delicada, con su cuerpo voluptuoso y fragante, el sufrimiento padecido en las cuevas lóbregas del arráez».

De forma consecuente las connotaciones eróticas de las moras las traslada Gerchunoff (1953:54) también a las mujeres judías, «la

\footnotetext{
10 Cf. ReHRManN 1996a.

1 También ubica en el mismo lugar la poesía erótica de Heine, a quien dedicó un libro (1927), cuando caracteriza (1927:74) al poeta como «español y oriental». En cambio no aborda el tema de la discutida procedencia sefardita de Heine (REHRMANN 1999a).
} 
mujer misteriosa ... de la judería», a la que un «alto señor cristiano» le hace visitas nocturnas: «Ese alto señor amaba a la mora o la judía por más que viviera en la condenación, pues no pudo resistir sus hechizos, al verla una vez».

Según su especulación (1953:121ss), incluso el mismo autor de El Quijote sucumbió posiblemente al encanto prohibido de la convivencia erótica, que Gerchunoff describe ampliamente como fenómeno social en consonancia con la realidad. Esa «dulce desconocida», «su último idilio de juventud», que debe haber inspirado a Cervantes para el conocido episodio de El Quijote, podría haber sido una mora o una judía: « ¿Era negro tu cabello como el de las moras que detrás de las celosías contemplaban el desfile de los cristianos cautivos, o era áureo y caído en húmedos rizos sobre la sien, como el de las madonas vivientes cuya presencia iluminaba la fosca lobreguez de las juderías?».

La audaz especulación de Gerchunoff sobre la vida amorosa de su guía literario-cultural puede que sean puras proyecciones en las cuales el recuerdo de Sefarad se conserva simplemente como un pensamiento-deseo histórico cultural. Pero lo que sí es auténtico es la imagen que pinta (1953:59) de las mujeres cristianas en los tiempos de Cervantes: «EI amor de la mujer española», dominado por un «espíritu de fatalidad», «es siempre trágico y anuda al deseo de dicha la resolución de morir».

La frase «Un oscuro hombre de tu América se inclina ante tu sombra», con la que se despide de su héroe en su primer libro sobre Cervantes (1953:154), es un homenaje al escritor mejicano Carlos Fuentes, el más conocido representante de las últimas huellas de una convivencia tricultural, cuyos componentes de linaje desde hace mucho habían sido reprimidos por el «maquiavelismo erótico».

Todavía otro aspecto de la herencia sefardita debe ser destacado aquí: el topos del amor por España de los sefardíes, divulgado con especial frecuencia por autores españoles (Rehrmann 1999), presenta, por lo menos en la obra temprana de Gerchunoff, notables matices críticos.

A diferencia de intérpretes cristianos y judíos, quienes hablan de reconciliación sin dedicarse especialmente a las razones de la persecución judía en la Edad Media tardía y su final expulsión y conversión forzada, Gerchunoff destaca que el recuerdo a España 
es disonante. Por un lado (1984:35) «el elogio de España ... la época en que el pueblo de Israel habitó el suelo español». Por otro, el país del fanatismo religioso y de la Inquisición, el país «(de) la maldición de la Sinagoga», cuyo recuerdo ocasiona en numerosos habitantes de la colonia verdaderos sentimientos de odio: « $i$ Que se hunda y que se pulverice. Yo jamás he podido recordar ... el nombre de España» -así habla un rabino- «sin que la ira me llene los ojos de sangre y el alma de odio. Quiera Dios, en sus justos castigos, convertirla en una hoguera sin fin, por haber torturado a nuestros hermanos y quemado a nuestros sacerdotes» (1984:35).

Sorprendentemente y de ningún modo en concordancia con la realidad histórica, el mismo rabino imputa manifiestamente al judío del medioevo tardío una decisiva complicidad con el final de la convivencia medieval, cuando hace seguir a la citada acusación una indirecta autoacusación: «Fue en España donde los judíos dejaron de cultivar la tierra y cuidar sus ganados. No olvide, mi querido rabí», le responde (1984:35) un colega, «lo que se dice en Zeroim, el primer libro del Talmud, al hablar de la vida del campo: Es la única saludable y digna de la gracia de Dios».

La insinuación del judío rico, por lo menos del judío regateador obsesionado por el dinero, resuena también en la dedicatoria que el autor puso al comienzo del libro (1984:13): «Los más fuertes y más grandes varones de Judea trabajaban la tierra; cuando el pueblo elegido cayó en cautividad y se dedicó a oficios viles y peligrosos, perdiendo la gracia de Dios ...». Por eso en la admiración por los gauchos argentinos vibra no solamente la intención de Gerchunoff de adquirir la «verdadera carta de ciudadanía», sino también la exigencia de regresar a los orígenes míticos del judaísmo: «Es una tierra donde todos trabajan ..." (1984:34), «como ... los hebreos de la antigüedad» (1984:126).

En los años posteriores estuvo, en cambio, Gerchunoff mejor informado sobre las razones que llevaron al violento final de la convivencia pluricultural: «Amaban los oficios manuales y la actividad de la inteligencia», escribe ahora (1940:143), «a la inversa de los detractores sistemáticos de los judíos, para quienes sólo tienen los judíos la avidez de las riquezas y la comprensión exclusiva del comercio, bien material». Porque los judíos más que en cualquier otro lugar estuvieron integrados en la vida social, trabajaron, según Gerchunoff, «en España ... en profesiones numerosas ...». Por 
eso, argumentaba, no hubieran tenido las leyes antijudías (1984: 145 ) «de ninguna manera ... una virtualidad en la vida social, porque el español, hasta que no apareció la Inquisición, hasta que no se aplicó la política de la tortura y del martirio, el español, nunca ha comprendido lo qué era un vejamen ni ha tenido el coraje de ofender a los hombres que integraban la comunidad española».

En su esfuerzo -desgraciadamente demasiado simplista- de liberar su patria cultural-histórica del estigma del antisemitismo, Gerchunoff no ve (1984:145) en realidad más que un principal culpable: el rey don Fernando, «(que) deseaba de esta manera obtener el dinero de moros y judíos ...».

El autor trivializa esta perspectiva ampliamente reducida de la historia cuando confiesa (1984:148ss): «No soy un historiador ...». Pero se siente seguro, sin embargo, cuando afirma: «... con el rey don Fernando el Católico comenzó en España la superfetación de lo equívoco, la política de la Inquisición, de exclusión humana, del anatema, del hierro caliente y del ahorcamiento ...». Sólo en Fernando, «(que) fué uno de los reyes más bajos que ha tenido la historia de España», ve Gerchunoff en acción al intrigante de «conflictos artificiales»; a su esposa real, en cambio, le otorga la absolución histórica: «... Fernando el Católico no fué un esposo digno de la genial y pujante doña Isabel».

La extrema personalización de la persecución judía, su reducción grotesca a una persona tiene, sin embargo, su propia lógica, la cual permite a Gerchunoff, a pesar de toda la crítica a las consecuencias brutales de esa política, la posibilidad de identificarse con España en una medida que es francamente desconcertante.

\section{3. «LA RAZA EN SU AUTÉNTICO VIGOR IMPULSIVO»: UN HOMENAJE A LA HISPANIDAD}

A primera vista Gerchunoff parece ser un representante de la «teoría de las dos Españas». En su primer libro sobre don Quijote expresó esta teoría de forma explícita (1953:142): «Hay dos Españas: la felipesca, o sea el país sumergido en la sombra de un pasado funerario, y el país viviente, de cuya médula extrajo Cervantes la esencia profunda del quijotismo ... Ésa es la España que ama$\operatorname{mos} \ldots \gg$.

Si se observan estas dos «realidades» con mayor exactitud, entonces se verá que en gran parte constituyen un fresco histórico 
glorificador que a los ojos de los exponentes peninsulares de la hispanidad podría tener total consistencia ${ }^{12}$; sirva como ejemplo (1953:32) «la hazaña de Lepanto», en la cual también Cervantes había participado y que su admirador argentino la siente como «la etapa cesárea», una etapa "(en que) actuaba la raza en su auténtico vigor impulsivo», en la que «los jugos primarios de su heroismo" no se habían gastado aún.

La expresión más clara de esta «etapa cesárea», según Gerchunoff (1953:142), fue el descubrimiento de América: «... los españoles ... vienen a nuestra América, a nuestra Argentina, con las manos prontas para el trabajo y reanudan con su actitud el insaciable caudal de energía de los descubridores. Ellos forman la España del Quijote» ${ }^{13}$. El paralelo político-real del célebre héroe de la novela lo encuentra Gerchunoff personificado en Carlos V «(que) ve el universo por escenario y aspira a someterlo dentro de un concepto positivo de fuerte dominio ...» (1953:31). Solamente con Felipe II comienza la decadencia de la «raza», sólo él «engendra con su prudencia sombría generaciones híbridas», sólo su regencia marca el comienzo del fin de «época tan castiza»: «el españolismo deja de serlo en sus líneas fundamentales» (1953:32).

Debemos tener siempre presente que el autor de este elogio de las peripecias históricas de la hispanidad no es un español de nacimiento a quien los cañones de Ayacucho hayan herido en su identidad nacional: aquí canta un judío argentino de origen ruso las «proezas" de un país cuyo supuesto resplandor -dejando de lado algunos fuegos fatuos ideológicos- se había apagado también entre los intelectuales latinoamericanos.

Más de una generación después del desastre de 1898 se encuentra Gerchunoff en un nivel de interpretación histórico-cultural semejante al que podrían haberse encontrado los liberales españo-

12 Por eso también el elogio siguiente aparecido de forma póstuma en su libro Retorno a Don Quijote (1951:82) no es de ninguna manera un faux pas: «Don Marcelino Menéndez y Pelayo, nunca arbitrario ni falloso en su juicio ...». Un juicio notable, si se piensa en las posiciones reaccionarias del polígrafo santanderino-por ejemplo sobre la Inquisición-, posiciones que contradicen diametralmente las opiniones liberales de Gerchunoff.

${ }_{13}$ En Retorno a Don Quijote parece deplorar (1951:93) que su autor no haya participado personalmente en el descubrimiento: «Miguel de Cervantes Saavedra estuvo por tentar el gran sueño de América, por acercarse a la selva de los trópicos de oro ...». 
les de la I República (1868-1874). Como estos critica la España de la Contrarreforma, por ejemplo en el caso de Felipe II: «Las piedras del Escorial son su biografía. Ninguna página puede describir su existencia sórdidamente austera como estos muros sombríos, rectos y áridos, en que ha querido encerrar el alma de la nación». En esta certera crítica se articula sobre todo la aflicción y la nostalgia por una supuesta «otra España», la de Carlos V, «hombre de recio manipuleo, desmesurado y brutal, de instinto y de impulso ...».

El eco de este nostálgico canto final a la «gloria» de la España imperial resuena todavía en las páginas de Retorno a Don Quijote. En el libro aparecido póstumamente se queja Gerchunoff (1951:64ss), pero no del apagado resplandor «de la vieja España», plasmado en «la impaciencia heroica de Don Juan de Austria». La «otra España», «la que amamos», la ve de cierta forma resucitada más allá del Atlántico: «Ese idealismo individualista que simbolizaba Don Quijote de la Mancha»-afirma (1951:77)-, «terminó por derribar, como a la caballería ficticia, las ruinas y los escombros de la monarquía universal, y por restablecerla en las márgenes de los ríos y en la ribera de los océanos americanos».

Según él España ha terminado de ser, por lo menos desde la perspectiva europea, una gran potencia y un monopolio político. Sin embargo, dice, después el país se ha transformado «por el quijotismo difuso y actuante» en algo diferente: «En un gran pueblo, paridor de pueblos».

Estas frases que reproducen literalmente el vocabulario típico del panhispanismo peninsular (Rehrmann 1996) se escuchaban en esos tiempos también en la Península, si bien con una base católico-nacional que Gerchunoff rechazaba por razones obvias ${ }^{14}$.

Esta «teoría de la prolongación» centrada en España debió tener gran aceptación entre una mayoría de los intelectuales peninsulares que encontraron asilo en diversos países latinoamericanos, incluyendo la Argentina y con los cuales tuvo quizás contacto ${ }^{15}$. También es probable que les hubiera gustado la imagen que

${ }^{14}$ En lugar de ello se muestra convencido (1940:149) de que España en gran parte había permanecido judía: «Y aun después de la expulsión de los judíos, la sangre que se sedimentó en España con las conversiones, ha seguido hirviendo en la arteria española y actuando como una fuerza calificadora y como un impulso volitivo de genialidad».

15 Sin embargo, en las obras de Gerchunoff no se encuentran datos concretos de tal posibilidad. 
pintaba Gerchunoff de la Argentina, por lo menos de sus «raíces españolas».

\section{EL PATRIOTISMO ARGENTINO Y «LA ANTIGUA METRÓPOLI»}

Muchos de los numerosos ensayos que escribió Gerchunoff sobre la Argentina y que han sido recogidos de forma póstuma en Argentina: País de advenimiento, podría haberlos escrito Ortega y Gasset, quien describió el país a orillas del Río de la Plata desde perspectivas análogas, transfigurándolo hegelianamente: «Somos los recién advenidos a la historia» (1952:8).

Ese espíritu lo muestra también Gerchunoff (1952:8) como fiel epígono del filósofo alemán, cuya representación eurocéntrica del Nuevo Mundo se refleja hasta en su vocabulario: «Argentina», escribe en Las imágenes del país (1952:130), uno de los ensayos del libro, posee un «desnudo rostro», «una limpia sonrisa de mocedad», es un país (1952:135) que no hace mucho tiempo ha superado «el período fetal». Y lo que es ahora se lo debe al Viejo Mundo (1952:113): «¿Qué son los varones de Mayo sino los hijos de la Enciclopedia, los discípulos de Juan Jacobo, los descendientes del humanitarismo tumultuario del siglo XVIII?». Y a ese pasado, en esto no tiene la menor duda (1952:112), pertenece el futuro: «Nuestro futuro está en recoger la herencia de Europa para enriquecerla con nuevos perfeccionamientos y embellecerla con nuevas cualidades. Dice Anatole France: "La América es una nueva Europa"». No puede faltar el concepto del Nuevo Mundo como «abastecedor de energía cultural», según el paternalista credo de esperanza de Hegel: "La humanidad nos tenía como una reserva de la civilización». Sin embargo, con un matiz importante que probablemente no le hubiera gustado al filósofo alemán de la historia, añade: «Pero, nos negamos a admitir la semejanza en el destino» (1952:131).

Este otro destino del Nuevo Mundo, tal como lo vio Gerchunoff, encuentra su principal explicación en la historia colonial, a la que sin embargo no designa (1952:62) de esa manera, por lo menos no en el caso de su nueva patria: «El origen de la Argentina es otro». El origen del Nuevo Mundo lo describe su panegírico (1952:67ss) como una especie de segunda historia de la creación, como realización de profecías paradisíacas: «Y la Atlántida apare- 
ció, en su infinitud numerosa, como la promisión aguardada». Para permanecer en esta representación, los demiurgos son los conquistadores españoles que insuflaron nueva vida al continente nuevamente resurgido - «la Atlántida»-: «La develó la fantasía española, que llenó inmediatamente al universo con la multiplicación de su resonancia».

El entusiasmo de Gerchunoff cuando canta la «génesis española» es casi infinito y crece hasta alcanzar la forma de un himno histórico: «El navegante español vió en cada terrón del suelo de América la veta de una mina y detrás de cada bosque, de cada margen de los ríos que atravesaba bajo las flechas de los indígenas, vió erguirse el perfil luminoso de metrópolis llameantes de pedrería. La ficción del Eldorado se le manifestó a cada paso, y el soldado, el prócer, el bandido, con el estandarte de Castilla, con la espada cruel, con la cruz vencedora, convirtieron a la tierra concreta, mensurable y laborable del Continente, en tierra de ilusión y de remisión».

Este cántico al descubrimiento de América contiene realmente algunas disonancias - «la espada cruel», etc.-, pero como en un parto -así lo sugiere el vocabulario casi religioso-, no puede llevarse a cabo sin dolores... Al contrario, desde la perspectiva de Gerchunoff (1952:62) sólo este «esfuerzo de aparición y de definición» es una razón para «que nuestro vínculo con la antigua metrópoli sea tan profundo y obedezca, más que a cualquier razón, a la razón primordial de la simpatía».

¿No es acaso sorprendente que las poblaciones autóctonas americanas estén ausentes de este panorama cultural? El indígena de América, que según Hegel deberían extinguirse «tan pronto como el espíritu se aproxime a él», tiene para el nuevo ciudadano argentino aprisionado en el eurocentrismo muy poco interés, el cual expresa en algunas frases lacónicas (1952:104ss): «¿Cuál es esa tradicion?», se pregunta peyorativamente. La respuesta: «Nada nos vincula con la memoria del inca o del azteca ... No nos sentimos sus continuadores, como que somos continuadores en América de la civilización europea ...».

Este autor, que había sufrido en Rusia y en Argentina las amargas experiencias de la persecusión racial, dice en otro pasaje (1952:112) que esta civilización tiene un solo color: «Pertenecemos a la humanidad blanca, a la comunidad de la cultura occidental». 
Y si se buscan modelos ejemplares en la propia historia, los encontraremos «en los períodos más inmediatos» (1952:105). Se refiere a la época postcolonial «(que) consistió en despojar el espíritu nacional de los residuos indígenas y gauchos» ${ }^{16}$.

En Domingo Faustino Sarmiento y sus correligionarios ve Gerchunoff a los constructores nacionales en acción que quitaban de en medio los residuos históricos con vistas al futuro: «Imaginaron para la Argentina los carriles de las comunidades civilizadas».

En vista de la hispanofilia cultural-histórica se pregunta uno si estas vías eran también adecuadas para los trenes españoles, o con otras palabras: ¿no contiene este cambio permanente de Gerchunoff entre sus preferencias europeas en general y su fidelidad inviolable a su «origen hispánico» una contradicción cardinal que contraría de forma sensible su «propósito de progreso patriótico» (1952:22)?

A fin de cuentas él mismo había escrito (1953:32) que los primigenios «jugos primarios de su heroísmo» de los tiempos de Cervantes se habían transformado en un «factótum», en «gloria desteñida» y en «espíritu monjil». Cuando Gerchunoff describe las aporías contra las cuales tenía que luchar el nacionalismo de comienzos del siglo XIX, aparecen también esas contradicciones de forma explícita: «Se salía de la oscuridad de la colonia»-echando aquí un vistazo hacia atrás manifiestamente poco hispanófilo- "y se entraba en el período de la creación práctica». Solamente después de la Independencia, cuando los «yugos metropolitanos» fueron sacudidos -repite (1953:94) esta crítica interpretación del dominio español-, comenzó la época (1953:145) «de la magnificación argentina» como «pueblo, que es un ser eterno ...».

No se debe a la casualidad el que las pocas alusiones críticas a la época de América dominada por España estén en relación directa con el sentimiento patriótico de Gerchunoff: en el orden jerárquico de las fidelidades culturales la nación ocupa con evidencia una posición cimera. A diferencia de la retórica caduca de los círculos conservadores, cuya vocación servía a «la Raza española, conquistadora y fundadora» (Senkmann 1983:17) como un predicado cultural de nobleza para legitimar privilegios sociales y políticos, en la sociedad de emigrantes el patriotismo de Gerchu-

${ }^{16}$ El mito juvenil de Gerchunoff, la esencia de la argentinidad, ya había fenecido hacía largo tiempo. 
noff (1953:80) está más bien orientado hacia el futuro: «... nuestro patriotismo no debe limitarse a la emoción poética o épica de recordar, sino a la emoción profunda de construir».

En este "patriotismo activo", como él lo llama (1953:81), parece articularse el pensamiento de que, a pesar de todas las declaraciones de credo por la nación argentina ${ }^{17}$ y por la herencia españolasefardita, la «carta de ciudadanía» de los nuevos emigrantes, sobre todo la de los judíos, no era suficiente para convertirse en ciudadano de pleno derecho.

Los excesos antisemitas de finales de los años treinta (Senkmann 1983:135) y los ataques personales a los que estuvo expuesto el propio Gerchunoff (Senkmann 1983:244) han debido dar a su «patriotismo activo» impulsos decisivos. El elemento central de este «patriotismo» en el cual la propia biografía debe estar contenida, consiste también en una permanente advertencia (1952:29) frente a aquellos entusiastas de los «pueblos ... étnicamente cohesivos» y que ven en la "promiscuidad humana» un factor de riesgo para la estabilidad del «hombre nativo».

El ejemplo argentino -argumenta contra tales tesis- «nos disuade de la seriedad de esa hipótesis». Más de una vez evoca en lugar de ello la atmósfera melting pot de su época juvenil: «Multitud de españoles, de italianos, de franceses, de alemanes, de judíos, de rusos, de nórdicos, se acercaban densamente, continuamente a Buenos Aires, se hacinaban en el Hotel de Inmigrantes ...) (1952: 21). La descripción de aquella atmósfera contiene rasgos iluminadores que suenan más como un idilio multi-cultural en miniatura extraño a la realidad, pero que desde la perspectiva del autor judío contiene sobre todo una utopía concreta, existencial: «Ya en los corredores del Hotel se iniciaba la fusión de razas con la aproximación simpática de los varones y mujeres recién venidos, que se prolongaba en el cruce de las familias rurales. Así aprendían la lección americana de fraternidad al consustanciarse en el gran fundamento étnico del país y comprendían que no subsistían bajo su cielo benigno las segregaciones, las divisiones, los aislamientos

\footnotetext{
${ }^{17}$ Según propia afirmación (1953:122), en sus años juveniles estuvo aun dispuesto a poner en práctica esas declaraciones de credo nacional; «Queríamos libertar las Islas Malvinas e imaginábamos en nuestro desconsuelo patrótico ... la bandera nacional, enarbolada allá por el último patriota, el último conciudadano que gobernó esa porción de suelo argentino».
} 
milenarios creados en el hemisferio maternal de la civilización, por la supervivencia del odio o la resistente dureza del egoísmo» (1952:21).

El caldo de cultivo de esta utopía, sin embargo, no lo constituyen solamente las capas étnico-culturales. La «antiquísima solidaridad de la amargura», como caracteriza (Liacho 1951:84) la estrategia judía de supervivencia en la diáspora, contenía también para él una dimensión universal de justicia social. Con su compromiso con Sacco y Vanzetti (Senkmann 1983:214) demostró Gerchunoff que tampoco le era indiferente este lado de la «dureza del egoísmo».

$\mathrm{Su}$ permanente amor por don Quijote debe estar en una muy estrecha relación con ello: «esa lanza de herrumbrada moharra», había ya escrito algunos años antes (1953:72) de la ejecución de ambos sindicalistas norteamericanos, «está al servicio de la justicia».

\section{De Sefarad hacia IsRael: ¿UN CíRCulo vicioso judío?}

Al final de su vida Gerchunoff fue dolorosamente consciente de que su «aculturación indirecta» era en gran parte un camino falso. La vocación por la «herencia» sefardita y española no ofreció al judío askenazí de Rusia ninguna garantía para que pudiera utilizar sin limitación «la carta de ciudadanía» argentina; por eso en vísperas del holocausto, «Esa falta de seguridad»-escribe (Senkmann 1983:240) - «ha mantenido al judío en la dificultad de asimilarse definitivamente, y lo mantiene aún porque se le "desasimilaba" violentamente con frecuencia, como sucede en Alemania, Hungría, Rumania e Italia ...».

Su hispanofilia no se dañó con las experiencias amargas del holocausto ${ }^{18}$. Eso lo ilustra su libro póstumo Retorno a Don Quijote, donde escribió (1951:84) sobre su ídolo español y seguramente también sobre la razón de ser de su propia hispanofilia: «Su casticismo ... no le viene de su purismo de estilista, de la penosa elucubración en el taller del literato, sino de su elemental identidad con lo recóndito de su país y de su pueblo. Ese casticismo de Cervantes no es un misterio gramatical sino un misterio de concepción».

18 De forma sorprendente Gerchunoff no tomó posición sobre la política española de salvación de judíos (REHRMANN 1999a). 
Su entusiasmada admiración por España y con ella su patriótica exaltación por la Argentina de los primeros años dejan lugar a una grave desilusión sobre su utilidad práctica y le conducen a una reorientación política: hacia Israel. Con palabras que suenan patéticas y que recuerdan a los gauchos judíos de antaño, relaciona (Nesbit 1951:170) sus nuevas esperanzas con el nuevo Estado: «Israel es el enorme milagro de nuestros tiempos. Es el grano de trigo extraído de una tumba milenaria que vuelve a florecer en los campos del decálogo ...».

En la prensa de peronistas y liberales se le reprochó su compromiso con Israel (Senkmann 1983:244) y de llevar adelante las razones de los «patriotas sionistas», obedeciendo con ello a una «doble lealtad». Un reproche cuya dirección política probablemente debe haber causado dolores al patriota argentino, pero cuya dimensión cultural entendida de otra forma refleja sólo en parte la lealtad de Gerchunoff...

\section{BIBLIOGRAFÍA}

AizenberG, Edna (1991): «Borges, Gerchunoff y el gaucho (judío)», Raíces (Buenos Aires) 1 págs. 28-29.

ANGEL, Marc (1995): «Algunos elementos de la vida espiritual sefardí: el legado de España», en Ángel Alcalá (ed.), Judíos, sefarditas, conversos: La expulsión de 1492 y sus consecuencias (Valladolid: Ambito) págs. 354-364.

BORGES, Jorge Luis (1951): vid. GERCHUNOFF Retorno.

ESPINOSA, Enrique (1951): «Alberto Gerchunoff y "Los gauchos judíos"”, Davar 31-32-33 págs. 61-70.

GERCHUNOFF, Alberto (1927): Enrique Heine: El poeta de nuestra intimidad (Buenos Aires - Madrid: Babel).

- (1940): «El espíritu judío en la cultura española», Judaica (Buenos Aires) $87 / 88$ págs. $142-149$.

- (1951): Retorno a Don Quijote; Prólogo de Jorge Luis Borges (págs. 7-11) (Buenos Aires: Ed. Sudamericana).

- (1952): Argentina: País de advenimiento (Buenos Aires: Ed. Losada).

- (1952): «Los judíos en la lengua castellana», en El pino y la palmera (Buenos Aires: Sociedad Hebraica Argentina) págs. 31-32.

(1953): La jofaina maravillosa: Agenda cervantina (Buenos Aires: Ed. Losada). 
- (1984): Los gauchos judíos (Buenos Aires: Aguila Argentina Ediciones).

- (1994): Entre gauchos y judios; Prólogo de Eliahu TOKER (págs. 9-19) (Buenos Aires: Biblos Argentina - Secretaría de Cultura).

GiUsti, Roberto F. (1951): «Nuestro homenaje a la memoria de Gerchunoff», Davar 31-32-33 págs. 5-8.

GrünBerg, Carlos M. (1951): «A Alberto Gerchunoff», Davar 31-32-33 pág. 57.

Kramer, Gudiño L. (1951): "Sobre la actualidad de "Los gauchos judíos"», Davar 31-32-33 págs. 114-127.

LiACHO, Lázaro (1951): «Gerchunoff judío», Davar 31-32-33 págs. 71-95.

NESBIT, Luis (1951): «El Néstor de la Literatura Argentino-Judía», $D a$ var 31-32-33 págs. $155-177$.

REHRMANN, Norbert (1996): Lateinamerika aus spanischer Sicht. Exilliteratur und Panhispanismus zwischen Realität und Fiktion (1936-1975) (Frankfurt: Vervuert).

-_ (1996a): «Literatur(geschichte) als Landeskunde: Das Beispiel der Erótica Hispánica», Hispanorama. Mitteilungen des Deutschen Spanischlehrerverbandes 74 (Nov. 1996) págs. 67-76.

- (1998): «El redescubrimiento de moros y sefardíes en la literatura española del siglo XIX y principios del XX», Raíces (Madrid) 36 (otoño) págs. 35-43.

- (1999): «Kulturelles Gedächtnis, nationale Identität und Literatur: Die Sephardenthematik in fiktionalen und essayistischen Texten des 19. und 20. Jahrhunderts - Entwicklungslinien und Desiderate», en Norbert RehrmanN - Andreas Koechert (eds.), Spanien und die Sepharden. Geschichte, Kultur, Literatur (Tübingen: Niemeyer) págs. 195-222.

_ (1999a): «Über "holde Ignoranz" und das "große Goldzeitalter": Heinrich Heine und das jüdisch-maurische Spanien», Tranvía, Revue der Iberischen Halbinsel 53 (Juni) págs. 18-21.

SENKMANN, Leonardo (1983): La identidad judía en la literatura argentina (Buenos Aires: Ed. Pardes).

SOTO, Luis E. (1954): «"Los gauchos judíos": Acta de fundación de un pueblo", Davar 50 págs. 121-129.

TIETZ, Manfred (1998): «Mittelalter und Spätmittelalter», en Hans-Jörg NEUSCHÄFER (ed.), Spanische Literaturgeschichte (Stuttgart - Weimar: Metzler) págs 1-68.

TOKER, Eliahu (1994): vid. Gerchunoff (1994) Entre gauchos. 


\section{RESUMEN}

Aunque de origen askenazí, el escritor argentino Alberto Gerchunoff se convirtió en infatigable propagador de la cultura española, especialmente de su herencia tricultural. Hasta hoy, el denominado Nestor de la literatura judía en Argentina es el representante más conocido en toda hispanoamérica de lo que se ha llamado «sefardización secundaria» de los judíos askenazíes.

\section{SUMMARY}

Although the Argentinian author Alberto Gerchunoff came from an Ashkenazi background, he proved to be a relentless supporter of Spanish culture, especially of its Jewish, Moorish, and Christian multi-cultural heritage. Considered the «Nestor» of Jewish literature in Argentina, he is still Latin America's most renowned representative of what has been called ethe subsequent Sephardization» of Ashkenazi Jews. 